\title{
Does increasing the number of inseminations per cycle increase the probability of conception? a randomized trial comparing single versus double intrauterine insemination
}

\author{
Yasaswi Khandavalli ${ }^{1}$, Seema Rai ${ }^{1 *}$, Rama Singodiya Lodha ${ }^{2}$
}

\begin{abstract}
${ }^{1}$ Department of Obstetrics and Gynecology, MH Bhopal, Bairagarh, Bhopal, Madhya Pradesh, India
${ }^{2}$ Department of Community Medicine, Gandhi Medical College, Bhopal, Madhya Pradesh, India
\end{abstract}

Received: 03 June 2020

Accepted: 09 July 2020

\author{
*Correspondence: \\ Dr. Seema Rai, \\ E-mail: seema73rai@hotmail.com
}

Copyright: (C) the author(s), publisher and licensee Medip Academy. This is an open-access article distributed under the terms of the Creative Commons Attribution Non-Commercial License, which permits unrestricted non-commercial use, distribution, and reproduction in any medium, provided the original work is properly cited.

\begin{abstract}
Background: Intrauterine insemination (IUI) remains an inexpensive, non-invasive, and effective first-line artificial insemination technique. The technique of IUI has evolved through various innovations since the time Cohen published the first report of IUI in 1962, and the success rate increased from $5 \%$ to $>20 \%$. The success of IUI depends upon several factors; two such prognostic factors are the timing and frequency of insemination. The objective of this study was to compare the effectiveness of single versus double intrauterine insemination.

Methods: This prospective randomized study was carried out in 130 patients with male factor infertility, PCOS and unexplained infertility. Patients were randomly assigned into two groups. In the first group of 65 patients, single IUI was applied at 36 to 40 hours after HCG administration, to the other 65 patients in the second group, double IUIs were applied at 12 to 16 hours and 36 to 40 hours after HCG administration. The primary end-point of the study was to compare the clinical pregnancy rate between the two groups.

Results: The overall pregnancy rate was $18.46 \%$ (12/65) for single IUI group and $30.76 \%$ (20/65) for double IUI group. There was a no statistically significant difference between single and double IUI groups $(\mathrm{p}=0.16)$.

Conclusions: This study did find a higher pregnancy rate following double IUI; however, the difference was not statistically significant. Further, larger sample size studies are required to determine if double IUI increases the pregnancy rate.
\end{abstract}

Keywords: Controlled ovarian hyper stimulation, Double, Insemination, Intrauterine insemination, Pregnancy rate, Single

\section{INTRODUCTION}

Infertility is a disease of the reproductive system and is defined by failure to achieve a clinical pregnancy after $\geq 12$ months of regular unprotected sexual intercourse. ${ }^{1}$ It has become a significant global problem with a considerable physical, psychological and social impact. Assisted reproductive techniques like intrauterine insemination (IUI), in vitro fertilization (IVF) and intracytoplasmic sperm injection (ICSI) are now considered the established treatment options for couples suffering from infertility. IUI involves intrauterine deposition of processed semen (partner/donor) at the expected time of ovulation. Controlled ovarian hyperstimulation $(\mathrm{COH})$ with IUI is approved costeffective, efficient, and the first line of treatment of choice for infertile patients with unexplained, mild male factor and ovulation disorders. ${ }^{2,3}$ Previous investigations reported 10\%-20\% success rate of clinical pregnancy by IUI. $^{3}$ Many factors can have a significant effect on the success rate of IUI. Two important factors that could be associated with the success rates are the timing and 
frequency of insemination. The rationale for double insemination is to create the opportunity for a longer fertilization period as multiple oocytes may rupture sequentially over a wide interval ( 22-47 hours) after HCG administration in OH/IUI cycles. ${ }^{4,5}$ Previous studies have reported conflicting findings regarding the success rate by single and double IUI. ${ }^{6-11}$ Based on a systematic review and meta-analyses, there is no systematic preference of the double IUI versus single IUI. ${ }^{12,13}$ The objective of the present study was to compare the effectiveness of single versus double IUI in controlled ovarian hyperstimulation cycles $(\mathrm{COH})$.

\section{METHODS}

This study was a prospective randomized study carried out in infertility patients who underwent IUI at a single center from March 2019 to March 2020. A total of 188 underwent IUI out of which 150 patients were enrolled in the study after meeting the following criteria.

\section{Inclusion criteria}

- Unexplained infertility

- Mild male factor infertility

- PCOS.

\section{Exclusion criteria}

- Blocked fallopian tubes

- Endometriosis

- Severe male factor infertility.

Each woman received only one cycle of treatment during the study. A detailed history, physical examination, laboratory tests, day 2/3 FSH/LH/AMH/PRL/FT3, FT4, TSH, semen analysis and culture, hysterosalpingography and laparoscopy were performed for patients included in the study. Male factor infertility was defined as semen concentration of $<15$ million sperms $/ \mathrm{ml}$, normal morphology $<4 \%$ (WHO criteria) and progressive motility of $<32 \%(\mathrm{~A}+\mathrm{B})$ before sperm preparation as per WHO guidelines. ${ }^{14}$ Oligospermia and asthenospermia or both in combination with $<10$ million sperm indicated mild male factor infertility. ${ }^{15}$ The cause of infertility is said to be unexplained when there is normal ovulatory function, semen analysis and patent fallopian tubes. Revised diagnostic criteria of polycystic ovary syndrome 2003 criteria (2 out of 3 )

- Oligo- or anovulation

- Clinical and/or biochemical signs of hyperandrogenism

- Polycystic ovaries and exclusion of other etiologies (congenital adrenal hyperplasia, androgen-secreting tumours, Cushing's syndrome). ${ }^{16}$

During the second or third day of their menstrual cycle, transvaginal ultrasound was performed for all participants to rule out ovarian cysts and assess endometrium, ovulation inductions were done for women without any abnormality.

\section{Ovulation induction}

All patients were given Letrozole (Letoval, Sunphrama) 5 $\mathrm{mg} /$ day for five days starting from day 2 or day 3 of the cycle; and recombinant FSH (rFSH) (Gonal F, Merek Serono) $75 \mathrm{IU}$ starting from day six or day seven and was continued by titrating dose depending on the growth of the follicle until the leading follicle reaches $>18 \mathrm{~mm}$ size. Follicular development was monitored by transvaginal ultrasound examination on alternate days starting from day six or day seven of the cycle. On day $6 / 7$ endometrial thickness was measured, tab Estradiol Valerate $2 \mathrm{mg}$ (Progynova, Bayer Zydus Pharma) three times a day was added if the endometrial growth was not consistent with follicular growth. When the dominant follicle was $>18$ $\mathrm{mm}$ in diameter, 10000 IU of human chorionic gonadotropin (FERTIGYN, Sun Pharma) (HCG) was administered intramuscularly. $\mathrm{COH}$ cycles with no follicular growth, with more than five dominant follicles of $>15 \mathrm{~mm}$ diameter and endometrial thickness of $<7 \mathrm{~mm}$ on the day of HCG administration or endometrial polyp were excluded from the study. As an alternative couple were asked to consider timed intercourse or converted to IVF cycle.

\section{Randomization}

A total 150 patients were enrolled in the study, out of which 20 patients were excluded from the study with more than five dominant follicles of $>15 \mathrm{~mm}$ diameter, no follicular growth noticed and with endometrial thickness of $<7 \mathrm{~mm}$ on the day of HCG administration or endometrial polyp. Rest of the 130 participants were randomly assigned to single and double IUI groups by a person not involved in the study using the block randomization method. In the first group of 65 patients, single IUI was done at 36-40 hours after HCG administration. In the second group of 65 patients, two IUI'S were done at 12-16 hours and 36-40 hours after HCG administration.

\section{Semen preparation}

Semen samples were obtained a few hours before the insemination. In this study density gradient centrifugation method was used for semen preparation. Approximately 1 $\mathrm{ml}$ of $90 \%$ Sperm Grad ${ }^{\mathrm{TM}}$ (Vitrolife, Sweden) was transferred into a tube, followed by $1 \mathrm{~mL}$ Sperm Grad $^{\mathrm{TM}}$ (Vitrolife, Sweden) 45\%. One ml of semen was gently placed on to the upper phase. The sample was centrifuged at $1,500 \mathrm{rpm}$ for 15 minutes, and the supernatant was discarded. After the first centrifugation, $2 \mathrm{ml}$ of HTF was transferred to resuspend the pellet. The pellet was gently mixed and the sample was centrifuged at 1,500 rpm for 10 minutes. After removing the supernatant, the final pellet was resuspended in $0.5 \mathrm{ml}$ of HTF. The sample was left for 20 minutes at 450 slanting, $0.5 \mathrm{ml}$ of supernatant 
is removed. The sample is now ready for insemination. Post wash examination was done to calculate the yield.

\section{Intrauterine insemination procedure}

Insemination was performed by using a sterile IUI catheter (Spermtrans IUI catheter, India) in lithotomy position, cervix was visualized by Cusco's speculum after the vagina and the cervix had been washed with normal saline. The catheter was gently passed through the cervical canal just above the internal os, and the sperm sample of around $0.5 \mathrm{ml}$ expelled into the uterine cavity slowly. Patients remained supine 15 minutes after IUI, intercourse after the procedure was forbidden for the rest of the cycle. The luteal phase was supported by Tab Dydrogesterone (Duphaston, Abbott) $10 \mathrm{mg}$ two times a day and Inj Hydroxyprogesterone Caproate (Proluton depot, Zydus healthcare LTD) $500 \mathrm{mg}$ intramuscular per week. All patients were called after 21 days from the day of HCG administration and tested for urine pregnancy test. Clinical pregnancy was diagnosed after the IUI by the evidence of gestational sac on transvaginal ultrasonography.

Baseline data including the women's age, husband's age, BMI (body mass index), day 2/3 FSH, LH, AMH levels, cause and duration of infertility, motility and sperm count, the number of dominant follicles on the day of HCG injection, endometrial thickness was collected. The incidence of clinical pregnancy, miscarriage, ectopic and multiple pregnancies were recorded and analysed.

\section{Statistical analysis}

The values were expressed as mean \pm Standard deviation (SD). The baseline differences between the two groups were analyzed by Chi-square test. A value of $\mathrm{p}<0.05$ was considered statistically significant. The statistical significance of the results was evaluated using web-based free statistical package by Social science statistics.

\section{RESULTS}

There was no statistically significant difference between the groups regarding women's age, their husband's age, women's BMI, duration of infertility, causes of infertility, the level of FSH, LH, AMH, the number of dominant follicles, endometrial thickness and pre-wash and postwash sperm parameters (sperm count and motility). The ages of both male and female partners, duration of infertility, causes of infertility, day 2/day $3 \mathrm{FSH}, \mathrm{LH}$, $\mathrm{AMH}$, the number of dominant follicles, endometrial thickness and pre-wash and post-wash sperm parameters in both the groups were shown in Table 1 .

Table 1: Baseline characteristics of the patients.

\begin{tabular}{|c|c|c|c|}
\hline Description & Single IUI $(\mathrm{N}=65)$ & Double IUI (N=65) & p value \\
\hline Age of the female (years) & $27.9 \pm 3.60$ & $26.53 \pm 3.11$ & 0.89 \\
\hline Age of male (years) & $31.05 \pm 3.42$ & $30.61 \pm 3.23$ & 0.92 \\
\hline BMI $\left(\mathrm{kg} / \mathrm{m}^{2}\right)$ & $24.27 \pm 5.10$ & $23.70 \pm 4.20$ & 0.96 \\
\hline Duration of infertility (years) & $5.06 \pm 1.75$ & $4.41 \pm 1.46$ & 0.74 \\
\hline \multicolumn{4}{|l|}{ Sperm count (million/ml) } \\
\hline Pre-Wash & $41.81 \pm 18.90$ & $42.141 \pm 19.61$ & 0.96 \\
\hline Post-wash & $31.36 \pm 16.59$ & $32.14 \pm 16.11$ & 0.89 \\
\hline \multicolumn{4}{|l|}{$\%$ progressive motile sperm } \\
\hline Pre-Wash & $51.20 \pm 14.37$ & $50.78 \pm 13.51$ & 0.92 \\
\hline Post-wash & $94.16 \pm 5.86$ & $95.80 \pm 3.66$ & 0.87 \\
\hline FSH on day $3(\mathrm{mlU} / \mathrm{ml})$ & $6.75 \pm 2.16$ & $7.20 \pm 3.15$ & 1.00 \\
\hline LH on day $3(\mathrm{mlU} / \mathrm{ml})$ & $6.44 \pm 3.89$ & $6.70 \pm 3.97$ & 0.84 \\
\hline AMH on day $3(\mathrm{ng} / \mathrm{ml})$ & $6.09 \pm 4.02$ & $4.93 \pm 3.25$ & 0.78 \\
\hline HCG day endometrial thickness & $1.02 \pm 0.14$ & $1.01 \pm 0.13$ & 0.32 \\
\hline Number of follicles of $>18 \mathrm{~mm}$ & $2.70 \pm 0.94$ & $2.51 \pm 0.860$ & 0.86 \\
\hline \multicolumn{4}{|l|}{ Diagnosis } \\
\hline PCOS & $\mathrm{N}=22(33.80 \%)$ & $\mathrm{N}=21(32.30 \%)$ & \multirow{3}{*}{0.94} \\
\hline Un-explained infertility & $\mathrm{N}=23(35.38 \%)$ & $\mathrm{N}=25(38.46 \%)$ & \\
\hline Male factor infertility & $\mathrm{N}=20(30.76 \%)$ & $\mathrm{N}=19(29.23 \%)$ & \\
\hline
\end{tabular}

Note: Values expressed as mean \pm Standard deviation (SD). No significant difference between groups.

The mean age of the male partner in years was $31.05 \pm 3.42$ in single IUI group and $30.61 \pm 3.23$ in double IUI group. When pregnancy was compared in single and double IUI group, it was found that pregnancy rate was higher in double IUI in all the age groups, $50 \%$ versus $75 \%$ in $20-25$ years, $28.50 \%$ versus $41.37 \%$ in $26-30$ 
years, $9.67 \%$ versus $17.85 \%$ in $31-35$ years. Double IUI has yielded a pregnancy rate of $25 \%$ in age groups of 36 to 40 years in comparison to no pregnancy in single IUI group (Table 2).

The mean female age in the study was $27.9 \pm 3.60$ in single IUI group and $26.53 \pm 3.11$ in double IUI group. Pregnancy rate has been found to be more in double IUI than single IUI in age group of $20-25$ years (41\% versus $25 \%$ ), in $26-30$ years $(31.25 \%$ versus $24.13 \%$ ), in $31-35$ years $(11.12 \%$ versus $10.52 \%)$. There was no pregnancy in both single and double IUI groups in age groups of 36 to 40 years (Table 3 ).
In this study, a better pregnancy rate was achieved in double than single IUI groups, i.e. $35.41 \%$ versus $17.07 \%$ in infertility up to 5 years duration. The pregnancy rate was more in double IUI than single IUI groups $(35.41 \%$ versus $20 \%$ ) respectively in infertility for 6 to 10 years duration (Table 4). No pregnancy could be achieved in those 2 women with infertility of more than 10 years. The overall pregnancy rate achieved according to the indication for IUI in the double IUI group was superior when compared to single IUI group. However, there was no statistically significant difference between the two groups $(\mathrm{p}=0.60)$ (Table 5).

Table 2: Male age specific pregnancy rate in single and double IUI.

\begin{tabular}{|lll|llll|}
\hline \multirow{2}{*}{ Age description (years) } & \multicolumn{2}{l|}{ Number of patients } & \multicolumn{2}{l|}{ Number of pregnancy } & \multicolumn{2}{l|}{ of pregnancy } \\
\cline { 2 - 7 } & Single IUI & Double IUI & Single IUI & Double IUI & Single IUI & Double IUI \\
\hline $20-25$ & 06 & 04 & 03 & 02 & $50.00 \%$ & $75.00 \%$ \\
\hline $26-30$ & 21 & 29 & 06 & 12 & $28.50 \%$ & $41.37 \%$ \\
\hline $31-35$ & 31 & 28 & 03 & 05 & $09.67 \%$ & $17.85 \%$ \\
\hline $36-40$ & 07 & 04 & 0 & 01 & $0 \%$ & $25.00 \%$ \\
\hline
\end{tabular}

Table 3: Female age specific pregnancy rate in single and double IUI.

\begin{tabular}{|lll|llll|}
\hline \multirow{2}{*}{ Age description (years) } & \multicolumn{2}{l|}{ Number of patients } & Number of pregnancy & \multicolumn{2}{l|}{ \% of pregnancy } \\
\cline { 2 - 8 } & Single IUI & Double IUI & Single IUI & Double IUI & Single IUI & Double IUI \\
\hline $20-25$ & 12 & 22 & 03 & 09 & $25.00 \%$ & $41.00 \%$ \\
\hline $26-30$ & 29 & 32 & 07 & 10 & $24.13 \%$ & $31.25 \%$ \\
\hline $31-35$ & 19 & 09 & 02 & 01 & $10.52 \%$ & $11.12 \%$ \\
\hline $36-40$ & 05 & 02 & 0 & 0 & $0 \%$ & $0 \%$ \\
\hline
\end{tabular}

Table 4: Duration of infertility and pregnancy rate in single and double IUI.

\begin{tabular}{|lll|llll|}
\hline $\begin{array}{l}\text { Duration of infertility } \\
\text { (years) }\end{array}$ & \multicolumn{2}{l|}{ Number of patients } & Number of pregnancy & \multicolumn{2}{l|}{ of pregnancy } \\
\hline Up to 05 & Single IUI & Double IUI & Single IUI & Double IUI & Single IUI & Double IUI \\
\hline $06-10$ & 41 & 48 & 07 & 17 & $17.07 \%$ & $35.41 \%$ \\
\hline Beyond 10 & 24 & 15 & 05 & 03 & $20.83 \%$ & $20.00 \%$ \\
\hline
\end{tabular}

Table 5: Clinical pregnancies achieved according to indication for IUI.

\begin{tabular}{|c|c|c|c|}
\hline Description & Single IUI & Double IUI & p value \\
\hline Anovulation & $02(09.09 \%)$ & $05(23.80 \%)$ & \multirow{3}{*}{0.60} \\
\hline Unexplained infertility & $07(30.43 \%)$ & $08(32.00 \%)$ & \\
\hline Male factor infertility & $03(15.00 \%)$ & $07(36.84 \%)$ & \\
\hline
\end{tabular}

Table 6: Clinical pregnancy achieved based on the number of follicles in both groups.

\begin{tabular}{|lllll|}
\hline & \multicolumn{2}{l}{ Single IUI No. of follicles } & \multicolumn{2}{l|}{ Double IUI No. of follicles } \\
Description & $\mathbf{3}$ & $\mathbf{3}$ & $\mathbf{3}$ & $\mathbf{3}$ \\
\hline Positive Pregnancy & $04(33.33 \%)$ & $08(66.67 \%)$ & $08(40.00 \%)$ & $12(60.00 \%)$ \\
\hline
\end{tabular}

In patients with $<3$ follicles the pregnancy rate was $33.33 \%(4 / 12)$ and in patients with $>3$ follicles the pregnancy rate was $66.67 \%(8 / 12)$ in single IUI group, and in double IUI group, the pregnancy rate was $40 \%$ and $60 \%$ for patients with $<3$ follicles and $>3$ follicles 
respectively (Table 6). A total 12 pregnancies were achieved in a single IUI group (18.46\%), 20 in double IUI group $(30.76 \%)$. Though higher pregnancy rates were achieved in double IUI group, there was no statistically significant difference $(\mathrm{p}=0.16)$ between both groups. In the single IUI group, 1 patient $(8.34 \%)$ and in the double IUI group, 2 patients $(10 \%)$ experienced miscarriage.
Ectopic pregnancy occurred in $1(5 \%)$ patient in the double IUI group, whereas there was no ectopic pregnancy in the single IUI group. Also, the incidence of multiple pregnancies in the single IUI group was $16.67 \%$ $(2 / 12)$, and in double IUI group was $20 \%$ (4/20). Furthermore, one patient in the double IUI group had triplet pregnancy $(\mathrm{p}=0.90)$ (Table 7).

Table 7: Clinical pregnancies in single and double IUI groups.

\begin{tabular}{|llll|}
\hline Description & Single IUI $(\mathbf{N}=\mathbf{6 5})$ & Double IUI $(\mathbf{N}=\mathbf{6 5})$ & p value \\
\hline Positive pregnancy & 12 & 20 & \multirow{2}{*}{0.16} \\
\hline Negative pregnancy & 53 & 45 & 30.76 \\
\hline \% of pregnancy & 18.46 & $02(10.00 \%)$ & 0.90 \\
\hline Miscarriage & $01(08.34 \%)$ & $01(5.00 \%)$ & \\
\hline Ectopic pregnancy & $00(0 \%)$ & $04(20.00 \%)$ & \\
\hline Multiple pregnancy & $02(16.67 \%)$ &
\end{tabular}

\section{DISCUSSION}

Despite revolutionary advances in the field of assisted reproduction such as in vitro fertilization (IVF), intracytoplasmic sperm injection (ICSI), intrauterine insemination (IUI) remains an inexpensive, non-invasive and effective first-line therapy for infertile couples. Though the technique has essentially remained the same, several advances in the stimulation protocols, gonadotropins, sperm preparation techniques and ultrasound monitoring have led to promising success rates with IUI. ${ }^{17}$ Changes in the frequency and the time of IUI are mentioned as significant factors to improve the chance of fertility by IUI. ${ }^{15,18}$ Combining $\mathrm{COH}$ with IUI was associated with better results than only $\mathrm{COH}$ in couples with unexplained infertility. ${ }^{19}$

Data from the Society of Assisted Reproductive technology and the American Society for reproductive medicine has stated that age was the only significant predictor of pregnancy rate. ${ }^{20}$ The study by Kang et al, supported the importance of the female age in the success of IUI. ${ }^{21}$ The decline in female fertility has been suggested to be a result of a decreased oocyte quality. ${ }^{22}$ In this study, though there was a significant decline in the pregnancy rate in females after 30 years of age, double IUI resulted in better pregnancy rate in all the age groups.

According to Matheiu and colleagues two factors are of poor prognosis, i.e., duration of infertility $>3$ years $(p=0.01)$ and increasing husbands age $(p=0.03) .{ }^{23}$ In the present study double IUI resulted in better pregnancy rate than single IUI in the male age group of 20 to 40 years. However, the difference was not statistically significant. Collins emphasized the importance of the duration of infertility on the prognosis and reported that the cumulative pregnancy rate decreased by $2 \%$ each year in patients 25 years and older and with duration of infertility of 3 years or longer. ${ }^{24}$ According to a study by Tomlimson MJ and colleagues, duration of infertility did not affect pregnancy rate significantly unless it had continued for more than 22 months. ${ }^{25}$ In this study, better pregnancy rate was achieved in couples with infertility up to 5 years, followed by infertility up to 6 to 10 years duration. Double IUI produced better pregnancy rate in both the groups of infertility up to 5 years and 6 to 10 years group. However, there was no statistically significant difference between the two groups.

Jameel et al, studied the significance of threshold effect for the average total motile sperm count with the average total motile sperm count of $<10 \mathrm{million} / \mathrm{ml}$, pregnancy rates were reported to be very low after IUI and when the average sperm count is above $30 \mathrm{million} / \mathrm{ml}$ a higher pregnancy rate is noted per IUI cycle. ${ }^{26}$ In Pathak et al, study better pregnancy rate was found in double IUI group than single IUI group in pre-wash sperm count of $>50$ million $/ \mathrm{ml}$, the difference was not statistically significant. ${ }^{27}$ In this study the prewash sperm count was $41.81 \pm 18.90$ and $42.14 \pm 19.16 \mathrm{million} / \mathrm{ml}$ and the prewash \% of progressive motile spermatozoa was $51.20 \pm 14.37$ and $50.78 \pm 13.51$ in single and double IUI groups respectively, and the post-wash sperm count was $31.36 \pm 16.59$ and $32.14 \pm 16.11$ and \% of progressive motile spermatozoa was $94.16 \pm 5.86$ and $95.80 \pm 3.66$ in both the groups respectively.

Stratified by indication for treatment, many studies reported no significant difference between single and double IUI. ${ }^{6,28,29}$ There are some studies that reported the superiority of double IUI. ${ }^{8,9,11}$ In this study, the overall pregnancy rate achieved according to the indication for IUI was superior in double IUI group when compared to single IUI group, but there was no statistically significant difference between the two groups. 
A recently published meta-analysis demonstrated that multi follicular growth is associated with increased pregnancy rates in OH/IUI cycles. ${ }^{30}$ ESHRE Capri Workshop Group (2009) report suggested that the success of multi-follicular cycles could be related to better ovarian reserve and perhaps better oocyte quality, rather than number of follicles. ${ }^{31}$ Bagis et al study, did not find any difference in LBRs between single and double IUI groups in $\mathrm{OH}$ cycles with multi follicular development. This findings are consistent with these findings, the overall pregnancy rates were $33.33 \%$ and $66.67 \%$ in cycles with $<3$ dominant follicles and $>3$ dominant follicles in single IUI groups respectively, and $40 \%$ and $60 \%$ in double IUI groups respectively.

The value of double IUI is still a subject of debate in the literature. A number of reports on the superiority of double IUIs after HCG administration can be found in literature. ${ }^{8,9,11,32,33}$ The authors of these studies have proposed that a second IUI improves the chances of conception, especially in $\mathrm{COH}$ with an unsynchronized ovulation pattern.

Ragni et al, data supported the hypothesis that two IUIs performed 12 hours and 34 hours after HCG administration is the most cost-effective regimen. ${ }^{11}$ Silverberg et al, compared single IUI performed 34 hours after HCG administration with a double IUI performed 18 hours and 42 hours after HCG administration, this study showed a statistically significant difference in favor of double IUI regimen. ${ }^{32}$ Abdalla et al, concluded that two IUIs performed 12 hours and 34 hours after HCG administration is the most cost-effective regimen for women undergoing $\mathrm{COH}$ cycles with clomiphene citrate and gonadotropins. ${ }^{33}$

Contrary to the previously mentioned reports, many studies have shown that second insemination in the same cycle is not as effective as the first. ${ }^{10,27,28,34-36}$ Casadei et al study, did not find any differences among the three groups, of patients who were given a single IUI at 36 hours, double IUIs at 12-36 hours, and a single IUI at 36 hours with timed intercourse on the HCG administration day. ${ }^{34}$ In another study, by Tonguc et al, double IUIs were shown to have no superiority over single IUI, according to pregnancy rates. ${ }^{10}$ In Matilsty et al study, the pregnancy rate was $9.7 \%$ in single IUI group and $37.9 \%$ per patient in the double IUI group. ${ }^{35}$ Gezgim $\mathrm{K}$ et al, study concluded no significant difference between single IUI applied at 36 hours, and double IUI applied at 24-46 hours after HCG administration. ${ }^{36}$

In Pathak et al, study pregnancy rate was (18.75\%) in double IUI group $(13.86 \%)$ in single IUI group, though higher pregnancy rates were observed in double IUI group, the difference was not statistically significant $(\mathrm{p}>0.05) .{ }^{27}$ Zahirini $\mathrm{Z}$ et al, reported a pregnancy rate of $11.7 \%$ in single IUI group and $13.4 \%$ in double IUI group and the difference was not statistically significant. ${ }^{29}$
Four meta-analyses were published on this topic. Osuna et al, demonstrated that double insemination (14.9\%) was not significantly better than single IUI $(11.4 \%) .{ }^{13}$ In other meta-analyses, the two insemination procedures were compared only in unexplained infertility patients and reported that there was no difference between the single and double IUI groups $(\mathrm{OR}=0.92 ; 95 \%$ CI $0.59-1.45$, $\mathrm{p}=0.715) .{ }^{37} \mathrm{In}$ a third analysis (Cantineau et al) the results favored double IUI over single IUI $(\mathrm{OR}=1.8,95 \% \mathrm{CI}$ : 1.4-2.4). ${ }^{12}$ Zavos A et al, in their meta-analysis, revealed a trend towards higher pregnancy rates among double IUI cycles (OR:1.58; 95\% CI: 0.59-4.21), but without statistical significance $(\mathrm{p}=0.20){ }^{38}$

The present study found higher pregnancy rates in double IUI group $(30.76 \%)$ as compared with a single IUI group $(18.46 \%)$. However, the difference was not statistically significant $(\mathrm{p}=0.16)$. The discrepancy between the results might be due to the differences in ovarian stimulation protocols, the timing of IUI, frequency of cycles, the inclusion criteria and randomization. In this study, the patients were followed up to 12 weeks of gestation, as this cohort was from different parts of the country who came to undergo infertility treatment from this study center. Therefore, authors suggest a follow-up period to assess the live birth rate.

\section{CONCLUSION}

In a developing country like India, it is important to achieve maximum success in an affordable cost Insemination is less stressful, invasive and economical than in vitro fertilization. Double insemination provides at least one insemination at an appropriate time with respect to ovulation and makes it possible to take full advantage of the window of opportunity for IUI. In conclusion, this study did find any increase rate in pregnancy following double IUI. However, the difference was not statistically significant.

In clinical trials of assisted reproductive techniques, the patient sample often is small because these studies require a long study period and are expensive to perform. However, larger and well-randomized trials are required to determine if double IUI can give better results

\section{Funding: No funding sources \\ Conflict of interest: None declared}

Ethical approval: The study was approved by the Institutional Ethics Committee

\section{REFERENCES}

1. Zegers-Hochschild F, Adamson GD, de Mouzon J, Ishihara O, Mansour R, Nygren K, et al. International committee for monitoring assisted reproductive technology; World Health Organization. The international committee for monitoring assisted reproductive technology (ICMART) and the World Health Organization (WHO) revised glossary on 
ART terminology. Hum Reprod. 2009;24(11):26837.

2. Guzick DS, Carson SA, Coutifaris C, Overstreet JW, Factor-Litvak P, Steinkampf MP, et al. Efficacy of superovulation and intrauterine insemination in the treatment of infertility. $\mathrm{N}$ Engl $\mathrm{J}$ Med. 1999;340(3):177-83.

3. Duran HE, Morshedi M, Kruger T, Oehninger S. Intrauterine insemination a systematic review on determinants of success. Hum Reprod Update. 2002;8(4):373-84.

4. Testart J, Frydman R. Minimum time lapse between luteinizing hormone surge or human chorionic gonadotropin administration and follicular rupture. Fertil Steril. 1982;37:50-3.

5. Abbasi R, Keingsberg D, Dnforth D, Falk RJ, Hodgen GD. Cumulative ovulation rate in human menopausal/human chorionic gonadotropin-treated monkeys: "step-up" versus "step-down" dose regimens. Fertil Steril. 1987;47:1019-24.

6. Alborzi S, Montazedian S, Parsanezhad ME, Jannati S. Comparison of the effectiveness of single and intrauterine insemination (IUI) double IUI per cycle in infertile patients. Fertil Steril. 2003;80:595-9.

7. Bagis T, Haydardedeoglu B, Kilicdag EB, Cok T, Simsek E, Parlakgumus AH. Single versus double intrauterine insemination in multi-follicular ovarian hyperstimulation cycles: a randomized trial. Hum Reprod. 2010;25(7):1684-90.

8. Liu W, Gong F, Luo K, Lu G. Comparing the pregnancy rates of one versus two intrauterine inseminations (IUIs) in male factor and idiopathic infertility. J Assit Reprod Genet. 2006;23:75-9.

9. Randall GW, Gantt PA. Double versus single intrauterine insemination per cycle: use in gonadotropin cycles and in diagnostic categories of ovulatory dysfunction and male factor infertility. J Reprod Med. 2008;53(3):196-202.

10. Tonguc E, Var T, Onalan G, Altinbas S, Tokmak A, Karakas N, et al. Comparison of the effectiveness of single versus double intrauterine insemination with three different timing regimens. Fertil Steril. 2010;94(4):1267-70.

11. Ragini G, Maggioni P, Guermandi E, Testa A, Baroni E, Colombo M, et al. Efficacy of double intrauterine in controlled ovarian hyperstimulation cycles. Fertil Steril. 1999;72(4):619-22.

12. Cantineau AE, Heineman MJ, Cohlen BJ. Single versus double intrauterine insemination in stimulated cycles for subfertile couples: a systematic review based on a Cochrane review. Hum Reprod. 2003; 18:941-6.

13. Osuna C, Matorras R, Pijoan JI, Rodrigues-Escuredo FJ. One versus two insemination per cycle in intrauterine insemination with sperm from patients' husband: a systematic review of the literature. Fertil Steril. 2004;82(1):17-24.

14. World Health Organization, Department of Reproductive Health and Research. WHO laboratory manual for the examination and processing of human semen. Switzerland: WHO Press; 2010.

15. Ragini G, Somigliana E, Vegetti W. Timing of intrauterine insemination: where are we? Fertil Steril. 2004;82(1):25-6.

16. ESHRE TR, Group A-SPCW. Revised 2003 consesus on diagnostic criteria and long-term health risks related to polycystic ovarian syndrome. Fertil Steril. 2004; 81(1):19-25.

17. Allahbadia GN. Intrauterine insemination: fundamentals revisited. The J Obstet Gynecol India. 2017;67(6):385-92.

18. Ransom M, Blotner M, Bohrer M, Corsan G, Kermmann E. Does increasing infrequency of intrauterine insemination improve pregnancy rates significantly during superovulation cycles? Fertil Steril. 1994;61(2):303-7.

19. Zeyneloglu HB, Arici A, Olive DL, Duleba AJ. Comparison of intrauterine insemination with timed inter-course in superovulated cycles with gonadotropin: a meta-analysis. Fertil Steril. 1998:69:486-91.

20. Society for assisted reproductive technology and the American Society for Reproductive Medicine. Assisted reproductive technology in the United States: 1998 American Society for reproductive Medicine/Society for Assisted Reproductive technology registry. Fertil Steril. 2002;77:18-31.

21. Kang BM, Wu TC. Effect of age on intrauterine insemination with frozen donor sperm. Obstet Gynecol. 1996;88(1):93-8.

22. Navot D, Goldstein N, MorJoset S, Simon A, Relou A, Birkenfeld A. Multiple pregnancies: risk factors and prognostic variables during induction of ovulation with human menopausal gonadotropins. Hum Reprod. 1995;6:1152-5.

23. Mathieu C, Ecochard R, Bied V, Lornage J, Czyba JC. Cumulative conception rate following intrauterine artificial insemination with husband's spermatozoa; influence of husband's age. Hum Reprod. 1995;10:1090-7.

24. Collins JA, Rowe TC. Age of the female partner is a prognostic factor in prolonged unexplained infertility: a multicenter study. Fertil Steril. 1989;52:15-20.

25. Tomlimson MJ, Arthur AJB, Thompson KA, Kasraie JL, Bentick B. Prognostic indicators for intrauterine insemination (IUI): Statistical model for IUI success. Hum Reprod. 1996;11(9):1892-6.

26. Jameel T. Sperm swim-up: a simple and effective technique of semen processing for IUI. J Pak Med Assoc. 2008;58(2):71.

27. Pathak B. Comparison of single versus and double intrauterine insemination. Int J Reprod Contracept Obstet Gynecol. 2017;6(12):5277-81.

28. Yavuz A, Demirci O, Sozen H, Uludogan M, Predictive factors influencing pregnancy rates after intrauterine insemination (IUI). Iran J Reprod Med. 2013;11(3):227-34. 
29. Sorouri ZZ, Shomali RR, Pourmarzi D. Single versus double intrauterine insemination in controlled ovarian hyperstimulation cycles: a randomized trial. Arch Iran Med. 2016;19(7):465-9.

30. Van Rumste MM, Custers IM, van der Veen F, van Wely M, Evers JL, Mol BW. The influence of the number of follicles on the pregnancy rates in intrauterine insemination (IUI): a meta-analysis. Human Reprod Update. 2008;14:563-70.

31. ESHRE Capri Workshop Group. Intrauterine insemination. Hum Reprod Update; 2009;15:265-77.

32. Silverberg KM, Johnson JV, Olive DL, Burns WN, Schenken RS. A prospective, randomized trail comparing two different intrauterine insemination regimens in controlled ovarian hyperstimulation cycles. Fertil Steril. 1992;57:357-61.

33. Ali AS, Essayed AA, Mabdelhady MA, Noreldin K, Allaha B. Comparative study between single and double intrauterine insemination in controlled ovarian hyper stimulation cycles. AAMJ. 2006;4(2):1.

34. Casadei L, Zamaro V, Calcagni M, Ticconi C, Dorucci M, Piccione E. Homologous intrauterine insemination in controlled ovarian hyperstimulation cycles: a comparison among three different regimens. Eur J Obstet Gynecol Reprod Biol. 2006;129:155-61.
35. Matilsky M, Geslevich Y, Ben-Ami M, Ben-Shlomo I, WeinerMegnagi T, Shalev E. Two-day IUI treatment cycles are more successful than one-day IUI cycles when using frozen-thawed donor sperm. J Androl. 1998;19:603-7.

36. Gezginç K, Görkemli H, Çelik Ç, Karatayli R, Çiçek $\mathrm{MN}$, Çolakoglu MC. Comparison of single versus double intrauterine insemination. Taiwan $\mathrm{J}$ Obstet Gynecol. 2008;47(1):57-61.

37. Polyzos NP, Tzioras S, Mauri D, Tatsioni A. Double versus single intrauterine insemination for unexplained infertility: a meta-analysis of randomized trials. Fertil Steril. 2010;94:1261-6.

38. Zavos A, Daponte A, Garas A, Verykouki C, Papanikolaou E, Anifandis G, et al. Double versus single homologous intrauterine insemination for male factor infertility: a systematic review and metaanalysis. Asian J Androl. 2013;15(4):533-8.

Cite this article as: Khandavalli Y, Rai S, Lodha RS. Does increasing the number of inseminations per cycle increase the probability of conception? a randomized trial comparing single versus double intrauterine insemination. Int J Reprod Contracept Obstet Gynecol 2020;9:3171-8. 